\title{
FINANCIAL INTERMEDIARIES' ASSET-LIABILITY DEPENDENCY AND LOW-INTEREST-RATE ENVIRONMENT: EVIDENCE FROM EU LIFE INSURERS
}

\author{
DOMENICO CURCIO*, , NICOLA BORRI ${ }^{\dagger, \|}$, \\ ROSARIA CERRONE ${ }^{t, * *}$ and ROSA COCOZZA $\$,{ }^{\prime \dagger}$ \\ *Department of Economics, Management, Institutions \\ University of Naples "Federico II" \& Centro Arcelli per gli Studi \\ Monetari e Fianziari LUISS, Naples, Italy \\ Department of Economics and Finance \\ LUISS University \& Centro Arcelli per gli Studi \\ Monetari e Fianziari LUISS, Rome, Italy \\ Department of Business Science-Management \& Innovation Systems \\ University of Salerno, Fisciano, Italy \\ $\S$ Department of Economics, Management, Institutions \\ University of Naples "Federico II", Naples, Italy \\ "domenico.curcio@unina.it \\ |nborri@luiss.it \\ **rocerro@unisa.it \\ †rosa.cocozza@unina.it
}

Accepted 4 March 2019

Published 10 April 2019

\begin{abstract}
This research studies the relationships between the two sides of life insurers' balance sheet and investigates whether and how they changed during recent past years, when European Central Bank monetary policy drove market rates to unprecedented low levels. By using a canonical correlation analysis, we study the internal structure of the links within and between the asset and liability sides of 24 major European Union (EU) life insurers' balance sheets over the 20072015 time horizon.

We find strong and substantial evidence that life insurers' assets and liabilities have become more independent over time. We argue that the declining trend of market interest rates has contributed to the generalized reduction in the linkage between the asset side and the liability side of EU life insurers, and has made insurance companies more exposed to ALM-related risks relative to the period before the financial crisis.
\end{abstract}

TCorresponding author.

This is an Open Access article published by World Scientific Publishing Company. It is distributed under the terms of the Creative Commons Attribution 4.0 (CC-BY) License. Further distribution of this work is permitted, provided the original work is properly cited. 
D. Curcio et al.

Keywords: Insurance companies; asset-liability dependency; balance sheet; interest rates; canonical correlation.

JEL Classification: G22, E43

\section{Introduction}

Life insurers' decisions concerning asset and liability management (ALM) depend on a complex set of economic and institutional factors, such as the regulatory constraints and the conditions prevailing in financial markets. From this latter perspective, the issues associated with the decline and the unprecedented low levels of market interest rates pose significant challenges for both the insurance industry and regulators. EIOPA has paid special attention to the interest rate risk across European life insurers (EIOPA 2016a, 2015), and in 2014 and 2016 it conducted industry-wide stress tests to assess the resilience of the European life insurance industry to a prolonged period of low interest rates (EIOPA 2014, 2016b). Based on EIOPA's last Financial Stability Report (EIOPA 2018), because of the prolonged low interest rate environment, the profitability of the insurance industry has experienced a significant deterioration and its solvency is at risk. Nevertheless, investigating the impact of interest rates on life insurers' activity is complex since changes in interest rates affect the balance sheet, investment income and premium rates, and, more in general, the demand for insurance products (Swiss Re 2012).

The impact of interest rates on a life insurer's balance sheet depends on a possible accounting mismatch and on the extent of the duration mismatch between assets and liabilities. As for the former, should assets be marked to market and liabilities be recorded at book value, a decline in interest rates will cause an increase in the insurer's equity. With regard to the latter, since life insurers' liabilities may have maturities longer than 30 years and, in some markets, assets with the same maturity are either unavailable or illiquid, a decline in interest rates threatens companies' profitability and can even cause solvency issues if rates stay low for long.

As far the pricing of insurance products is concerned, in life insurance, given a certain level of benefits, a decrease in interest rates increases the premiums paid by the policyholders. For example, the annual payments required to obtain the same benefits when interest rates are at $4 \%$ are lower than the payments needed if investment returns stand at $2.5 \%$. From a broader perspective, a reduction in interest rates can have different impacts on the demand for life insurance products. On the one hand, declining interest rates can either make these products more expensive or reduce their benefits, like in the case of an annuity, where, due to lower interest rates, the present value of the future lifetime payments rises and, consequently, the corresponding lump sum premium must rise to keep benefits at the same level. On the other hand, a reduction in interest rates can have a positive impact on some savings products providing returns higher than market rates.

Furthermore, a decline in interest rates significantly affect life insurers' profitability since they invest most of their premium income in high-quality bonds and, 
therefore, investment income is a major source of earnings for them. Nevertheless, even if the sensitivity of life insurance products to changes in interest rates can be very high, income response to a change in interest income is slow because insurers invest only current premiums at current market yields.

Finally, the impact of interest rates on life insurers depends also on policyholders' behavior, which in some circumstances is far from being rational. Some insurance products give to policyholders options whose exercise can affect insurers' exposure to interest rate risk, such as the options to extend the term of the policy or to increase the payments or the insured sum originally set in the contract. Therefore, assuming that the embedded interest rate guaranteed by a contract is higher than market rates, policyholders have the incentive to extend the contract beyond the original maturity, or to increase premium payments/the sum insured if the original interest rate is guaranteed.

In this paper, we tackle the issue of the impact of interest rates on life insurers' activity following an integrated-ALM perspective, based on balance sheet data. From our view, life insurance companies take the decisions concerning the assets to buy and the liabilities to sell under a condition of uncertainty and the outcomes of such a decision process involve interactions among the assets, among the liabilities and between the asset and liability sides of the balance sheet. The purpose of this research is to uncover the relationships between life insurers' assets and liabilities and to investigate how these relationships evolved during past recent years, when ECB's monetary policy decisions drove market rates to unexperienced low levels. In particular, by assuming that the structure of a life insurer's assets is a function of the structure of its liabilities, we contribute to prior literature investigating financial institutions' ALM by testing the hypothesis that assets of a life insurer have multiple correlation patterns with its liabilities and surplus categories. We also investigate the nature and the strength of the relationships between the two sides of the balance sheet.

We run our empirical analysis by using a canonical correlation estimation technique. Canonical correlation analysis, introduced by Hotelling (1935), unlike regression analysis, which relates a single-dependent variable to a linear combination of independent variables, correlates linear combinations of two sets of variables. Canonical correlation analysis considers variation within each set of variables and between the two sets, while regression considers only variation within one set of independent variables and between one dependent variable and that set. Therefore, canonical correlation analysis is an appropriate technique for analyzing relationships between the securities bought and sold by an intermediary (and represented as assets and liabilities in the intermediary's balance sheet) because these securities are correlated both within each side of the balance sheet and between the two sides of the balance sheet. More in details, we first assess the relationships within the assets and within the liability of the balance sheet, by separately taking into account each of the two sides of the balance sheet. Then, under a joint perspective, we study the links of asset accounts with liability accounts. Even if the analysis of canonical correlations provides an excellent statistical tool, our results have to be interpreted with caution because the 


\section{Curcio et al.}

analysis of balance sheet data is not able to comprehensively capture the complexity of the issues investigated here, which is essentially given by the above discussed numerous channels through which low interest rates affect life insurers. Therefore, additional qualitative and quantitative evidence could improve our understanding.

This research considers 24 major life insurers from 11 European Union (EU) countries, representing circa $56 \%$ of the whole EU insurance industry in terms of total assets (as of December 2015), and whose behavior is observed over the 2007-2015 horizon. As of December 2017, the overall European insurance industry roughly accounts for $30 \%$ of the global insurance market and European life premiums ( $€ 710$ billion) represent $32 \%$ of 2017 global life premiums (Insurance Europe 2018). We decided to focus on the EU life insurers not only for the seize of the industry, but also because they have traditionally made large use of insurance products with minimum guaranteed rates of return and profit sharing mechanism. In times of low interest rates, this might represent not only a threat for insurers' profitability, but it might also endanger their solvency position and, eventually, due to their relevance and strong interconnections with other financial intermediaries, it might represent a threat for the financial system as a whole. Based on our results, life insurance companies seem to run their business as if they decide their funding policies after identifying good investment opportunities. We find strong and substantial evidence that insurers' assets and liabilities have indeed become more independent over time. We argue that the declining trend of market interest rates over the examined time horizon has contributed to the generalized reduction in the linkage between the asset side and the liability side of EU life insurers, and has made insurance companies more exposed to ALM-related risks relative to the period before the financial crisis broke out.

The rest of the paper is organized as follows: Section 2 provides a review of the literature investigating the exposure of life-insurers' activity to interest rate risk and of the few previous studies using canonical correlation technique to investigate insurers' ALM; in Sec. 3, we present the rationale for using canonical correlation analysis and outline its application to this research; Sec. 4 describes our life insurer sample and the variables we use in our analysis; in Sec. 5 we discuss the main results of our empirical analysis; Sec. 6 provides concluding remarks.

\section{Interest Rates and Life Insurers' Asset and Liability Management: A Literature Review}

According to prior research (Berdin et al. 2015), there are two main channels through which low interest rates affect insurers': the "income channel" and the "balance sheet channel". Based on the former, low long-term interest rates make it increasingly hard for insurers to achieve investment returns in excess of guaranteed returns embedded in policies issued in the past. The "balance sheet channel" rests on a valuation effect: low yields result in an increase in the values of both assets and liabilities. The rise of the liabilities is higher than that of the assets because the assets invested in fixed-term instruments are a fraction of the total liabilities. From this perspective, relative to nonlife 
sectors, life insurers experience a higher exposure to interest rate declines because of the higher duration mismatch between assets and long-term life insurance liabilities.

Antolin et al. (2011) have examined the impact of protracted periods of low interest rates on insurance companies. From a financial stability perspective, they point out two major concerns: the first is that insurers may search for higher yields via riskier investments ("gambling for redemption" behavior); the second is the decline in interest rates causing an interest-risk-hedging activity that might further reduce bond yields (this has been confirmed for German life insurers by Domanski et al. 2015). From an ALM perspective, if their liabilities are characterized by longer duration than assets, insurers have to deal with the reinvestment risk associated with the fall of interest income due to the rollover into lower-yielding debt both of the coupon payments from fixed-income instruments and of the principal from maturing debt. Overall, the impact of low interest rates seems to depend on the contribution of investment income to the overall profitability: the greater is the contribution of interest income to an insurer's profitability, the larger is the fall in its profitability when interest rates stay low for a long period. With regard to the second source of concern just mentioned above, based on an empirical analysis of German life insurers, Domanski et al. (2015) actually show that German insurers buy more long date bonds to improve their matching strategy and further push down yield on bonds.

In their analysis of the impact of interest rate levels on the financial performance of a sample of 127 European insurers, Berdin et al. (2015) show the complexity of these two channels. In particular, they find that long-term interest rates have a positive impact on insurers' return on assets, with a bigger (and more statistically significant) impact on small and medium-sized companies and the life and health sectors. At the opposite, the long-term yields does not affect large insurers, which may result from their superior diversification ability, or the property and casualty sector, probably because nonlife insurance is characterized by a short pay-out pattern and by contracts made on a yearly basis with the possibility to increase prices at renewal. The authors also provide a model-based scenario analysis to assess in a forward-looking manner the effects of a prolonged period of low interest rates on the solvency and profitability of a representative life insurer active in Germany, France, Italy and the Netherlands. Their results show that: (i) the negative effect would be more pronounced in the case of a high volatility in financial returns, and (ii) specific characteristics of the company (duration mismatch, asset allocation, etc.) matter in determining the extent of the impact.

Berdin \& Gründl (2015) assess and quantify the effects of the low interest rate environment on the balance sheet of a representative German life insurer, given the current asset allocation and the outstanding liabilities. In particular, they generate a stochastic term structure of interest rates and stock market returns to simulate investment returns of a stylized life insurance business portfolio in a multi-period setting. To take into account different scenarios and to check the robustness of their results, the authors calibrate different capital market settings and different initial situations of capital endowment. Their results suggest that a prolonged period of low 


\section{Curcio et al.}

interest rates would markedly affect life insurers' solvency, leading to a relatively high cumulative probability of default, especially for less capitalized companies. The German insurance sector is the object of a previous paper by Kablau \& Wedow (2012) also, who develop a different approach to assess life insurers' resilience to a protracted period of low interest rates. Based on their results, a relatively large number of German life insurers would not be able to meet the minimum regulatory capital requirements set by Solvency I if the interest rates were to stay sufficiently low for long.

There are two approaches to measure life insurers' exposure to interest rate risk: bottom-up and top-down. The former would use detailed data on assets and liabilities and would allow estimating the interest rate risk of each company or even of each of the products sold by a certain insurer. According to the latter, since stock analysts take into account the product mix and interest rate guarantees of the products sold by the insurers, their stock price reflects the sensitivity of their liability to interest rate movements. By using a top-down based approach, Hartley et al. (2016) measure the exposure to interest rate risk of U.S. and U.K. insurers through a two-factor model of life insurer stock returns. Their empirical evidence shows that, despite being exposed to similar changes in interest rates, U.S. life insurers experienced an increase in their risk exposure as interest rates strongly decreased in recent years, whereas in U.K. life insurers' risk remained low and roughly at the same level observed prior to the financial crisis. According to the Authors, these differences are due to the more widespread use of products that combine guarantees with options for policyholders to adjust their behaviour by U.S. life insurers relative to their U.K. counterparts.

Berdin et al. (2017) develop an analytical framework for a forward-looking assessment of insurers' profitability and solvency by modeling the balance sheet of an insurance company involved in both life and nonlife business. The balance sheet is calibrated using country level data to make it representative of the major euro area insurance markets, and then projected forward under stochastic capital markets, stochastic mortality developments and stochastic claims. The research focuses on European markets where the relatively high guarantees and generous profit participation schemes make the insurers largely exposed to reinvestment risks. The results suggest that insurers more exposed to products with financial guarantees display a marked reduction in both profitability and solvency over time. The specific local regulation and the business practices (e.g. the minimum return guarantees and duration mismatches) significantly affect both profitability and solvency. As the business portfolio becomes more diversified and less concentrated on interest rate sensitive business, both profitability and solvency improve. By assuming a group perspective, if capital redistribution within the group is allowed, a low interest rate environment might also negatively affect the solvency position of the nonlife business, generally characterized by a limited exposure to interest rate risk, due to both lower return on assets and, most importantly, to the capital redistribution from the nonlife towards life business.

Prior studies have investigated widely the issues associated with a proper valuation and management of interest rate risk in the insurance sector. In particular, there is a huge literature dealing with the valuation of life insurance 
policies with a minimum guaranteed rate of return and a profit participation scheme (see, among the others, Grosen \& Løchte Jørgensen 2000, Bauer et al. 2006, Zaglauer \& Bauer 2008). As concerns asset-liability management and hedging strategies, Lee \& Stock (2000) examine the duration and convexity matching strategies to hedge interest rate risk, and Gerstner et al. (2008) developed an integrated asset and liability model where a portfolio of different life insurance policies evolve over time depending both on mortality developments and on the asset return generated by the investment portfolio.

Due to the peculiarities of the insurance business, interest rate risk has been studied jointly with the longevity risk. Mahayni \& Steuten (2013) examine the effect of stochastic longevity and stochastic interest rates on a portfolio of deferred annuities. By focusing on solvency requirements based on the investment decisions and the associated shortfall probability of the annuity provider, they conclude that the impact of stochastic mortality is low if compared to the impact of stochastic interest rates. Berdin (2016) assesses the effect of interest rate risk and longevity risk on the solvency position of a life insurer selling policies with minimum guaranteed rate of return, profit participation and annuitization option at maturity. Following their methodology, an existing banking book of policies and an existing asset allocation calibrated on observed data are projected forward according to different scenario built based on stochastic financial markets and stochastic mortality developments. Among these scenarios, the authors focus on a prolonged period of low interest rates and huge decrease in mortality rates. Even their results show that interest rate risk is definitely the major threat to life insurers, whereas longevity risk can be easily mitigated mainly through product design and prudential pricing.

As the studies using canonical correlation analysis to investigate the relationships between asset and liability accounts of financial intermediaries' balance sheets are concerned, this technique has not been specifically used to study the impact of interest rates on insurers' ALM, and prior research is mostly focused on banks (see Simonson et al. 1983, DeYoung \& Wom 2008, among the others). Within the insurance literature, the seminal work of Stowe \& Watson (1985) is the first to use a canonical correlation approach to study the relationships between the assets and liabilities of US life insurers' balance sheets. This analysis is important as the structure of asset and liability depends on interactions among the assets, among the liabilities, and between assets and liabilities, on top of the constraints induced by regulation and financial market conditions.

Stowe \& Watson (1985) work builds on the idea that life insurers solve a portfolio optimization problem when structuring their assets and liabilities. They follow an approach according to which the mean-variance model, based on Markowitz (1952) classic theoretical framework, provides a simple explanation of financial intermediation, where securities positively held can be thought as intermediary's assets and those negatively held as intermediary's liabilities. Instead of focusing on either the asset or the liability side of the balance sheet, this approach allows to incorporate 


\section{Curcio et al.}

explicitly dependencies between assets bought and liabilities sold by a financial intermediary.

Pyle (1971), Francis \& Archer (1979) and Francis (1978) use a mean-variance model to study the optimal balance sheet structure of financial intermediaries, where the optimal balance for each asset and each liability is a function of the expected returns on each assets and the expected costs of each liability as well as the covariances between all assets and liabilities. Stowe (1978) applies a similar meanvariance framework to life insurers.

\section{The Canonical Correlation Analysis: Mathematical Framework and Application to this Research}

This paragraph provides a description of the canonical correlation technique, developed by Hotelling $(1935,1936)$, in order to clarify the rationale for adopting it in our study. Canonical correlation is a multivariate analysis technique describing the relationships between two sets of variables, named criterion variables and predictor variables. In our case, these two sets of variables are, respectively, the asset and liability/capital accounts of an insurer's balance sheet.

Let the asset and liability/capital variables be denoted, respectively, by the matrices $X$ and $Y$. The number of rows of each matrix represents the $n$ insurers of our sample, while the number of columns indicates the different categories of asset $\left(q_{1}\right)$ and liability $\left(q_{2}\right)$ taken into account in our analysis. Consequently, $X$ is $n \times q_{1}$ and $Y$ is $n \times q_{2}$. The variables used are expressed as a proportion of total assets.

The canonical correlation methodology attempts to find linear combinations of $X$ and $Y$ so that the correlation between them is as high as possible. The linear combinations of $X$ and $Y$ are denoted, respectively, by $u_{i}$ and $v_{i}$ :

$$
\begin{gathered}
u_{i}=X a_{i}, \\
v_{i}=Y b_{i}, \\
i=1, \ldots, p \quad \text { with } p=\min \left(q_{1}, q_{2}\right),
\end{gathered}
$$

where $a_{i}$ and $b_{i}$ are vectors to be estimated and are, respectively, $q_{1} \times 1$ e $q_{2} \times 1$. We refer to the scalars that constitute the vectors as canonical coefficients, to the linear combinations of $X$ and $Y$ as canonical variables and to the correlations between the canonical variables as canonical correlation coefficients.

The canonical correlation coefficients and the canonical coefficients are obtained by solving the following equations ${ }^{\mathrm{a}}$ :

$$
\left\{\begin{array}{l}
\left(R_{11}^{-1} R_{12} R_{22}^{-1} R_{21}-\lambda_{i} I\right) a_{i}=0 \\
\left(R_{22}^{-1} R_{21} R_{11}^{-1} R_{12}-\lambda_{i} I\right) b_{i}=0
\end{array}\right.
$$

where $R_{11}$ is the covariance matrix between asset variables; $R_{22}$ is the covariance matrix between liability variables; $R_{12}$ is the covariance matrix between asset and liability variables, $R_{21}$ is its transposed and $I$ is the identity matrix.

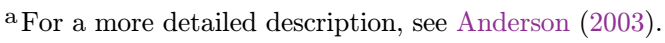


Equations (3.2a) and (3.2b) can be rewritten as systems of $p$ linear equations in $p$ unknown coefficients. These systems of linear equations will have nontrivial solutions only if their determinants are zero.

$$
\begin{aligned}
& \left|R_{11}^{-1} R_{12} R_{22}^{-1} R_{21}-\lambda_{i} I\right|=0, \\
& \left|R_{22}^{-1} R_{21} R_{11}^{-1} R_{12}-\lambda_{i} I\right|=0 .
\end{aligned}
$$

The largest value of $\lambda$ that satisfies both equations (3.2a) and (3.2b) is the first characteristic root, or, in other words, the first eigenvalue, of the following matrices:

$$
\begin{aligned}
& R_{11}^{-1} R_{12} R_{22}^{-1} R_{21}, \\
& R_{22}^{-1} R_{21} R_{11}^{-1} R_{12} .
\end{aligned}
$$

Vectors $a_{1}$ e $b_{1}$ are its corresponding eigenvectors, which constitute the weights (canonical coefficients) for the linear combinations $u_{1}$ and $v_{1}$. The first canonical correlation coefficient $\left(R_{1}\right)$ is the square root of the first characteristic root. In symbols:

$$
R_{1}=\sqrt{\lambda_{1}}
$$

Particularly, there will be a number $p$ of canonical correlation coefficients equal to the minimum between $q_{1}$ and $q_{2}$.

Canonical correlation coefficients represent the variance shared by linear combinations of assets and liabilities. Each successive canonical correlation coefficient will be smaller than the last since each successive root will explain less and less of the data. For each canonical correlation coefficient, we have different pairs of canonical variables. Each pair of canonical variables is uncorrelated with the others.

In order to determine the number of statistically significant canonical correlation coefficients, we use the test proposed by Bartlett (1941) which tests the null hypothesis that there is no relationship between the predictor and the criterion variables, or that there are no more than $k$ significant canonical pairs, where $k$ is equal to zero. When this hypothesis is rejected, $k$ is set equal to 1 and Bartlett's test is performed for this new value until the significance level is exceeded and the number of statistically significant canonical pairs is determined.

Since the variables used in our study are expressed as a proportion of total asset the sum of these proportions add to unity, which makes $R_{11}$ and $R_{22}$ singular. To avoid this singularity, we eliminate one variable from each set. The informational content of the remaining $q_{1}-1$ and $q_{2}-1$ variables does not change. Consequently, the number of canonical correlation can be lower than the minimum between $q_{1}-1 \mathrm{e}$ $q_{2}-1$. In symbols we can have:

$$
p \leq \min \left(q_{1}-1 ; q_{2}-1\right) .
$$

The nature of the relations between asset and liability can be studied by examining the canonical loadings, which are the correlation between the original variables and their own canonical variables. The canonical loadings give a measure of the total amount of variance in the actual data accounted for by the canonical variables; they are the elements of the matrices $S_{1}$ and $S_{2}$, with dimension $q_{1} \times p$ and $q_{2} \times p$, 


\section{Curcio et al.}

obtained as follows:

$$
\begin{aligned}
& S_{1}=\frac{1}{n} X^{\prime} V=\frac{1}{n} X^{\prime} X A=R_{11} A, \\
& S_{2}=\frac{1}{n} Y^{\prime} U=\frac{1}{n} Y^{\prime} Y B=R_{22} B,
\end{aligned}
$$

where $U$ and $V$ are $n \times p$ matrices whose columns contain the canonical variables obtained by solving (3.2a) and (3.2b). $A$ and $B$ are matrices with dimension, respectively, $q_{1} \times p$ and $q_{2} \times p$, whose columns are formed by the eigenvectors of the characteristics roots. Following Cliff \& Krus (1976), we rotate simultaneously the canonical loadings using Kaiser (1958) normalized varimax criterion. This simplifies the interpretation of the nature of the relationships between the canonical variables without affecting the total predictable variance.

Each element $S_{j k, 1}$ and $S_{j k, 2}$ of matrices $S_{1}$ and $S_{2}$ is the correlation coefficient between the $j$ th asset/liability variable and the $k$ th asset/liability canonical variable (for $j=1,2, \ldots, q_{1} / q_{2}$ and $K=1,2, \ldots, p$ ). The canonical correlation coefficients and the canonical loadings can be used to study the nature of the relationship between a specific asset and a specific liability. Its underlying logic is represented in Fig. 1 below and can be explained as follows. If the canonical correlation coefficient between two canonical variables is large (relation 1 ), and the canonical loadings for a specific asset $q_{1}$ (relation 2a) and a specific liability $q_{2}$ (relation $2 \mathrm{~b}$ ) are both large, we can assume that the specific asset $q_{1}$ and the specific liability $q_{2}$ are interconnected (relation 3).

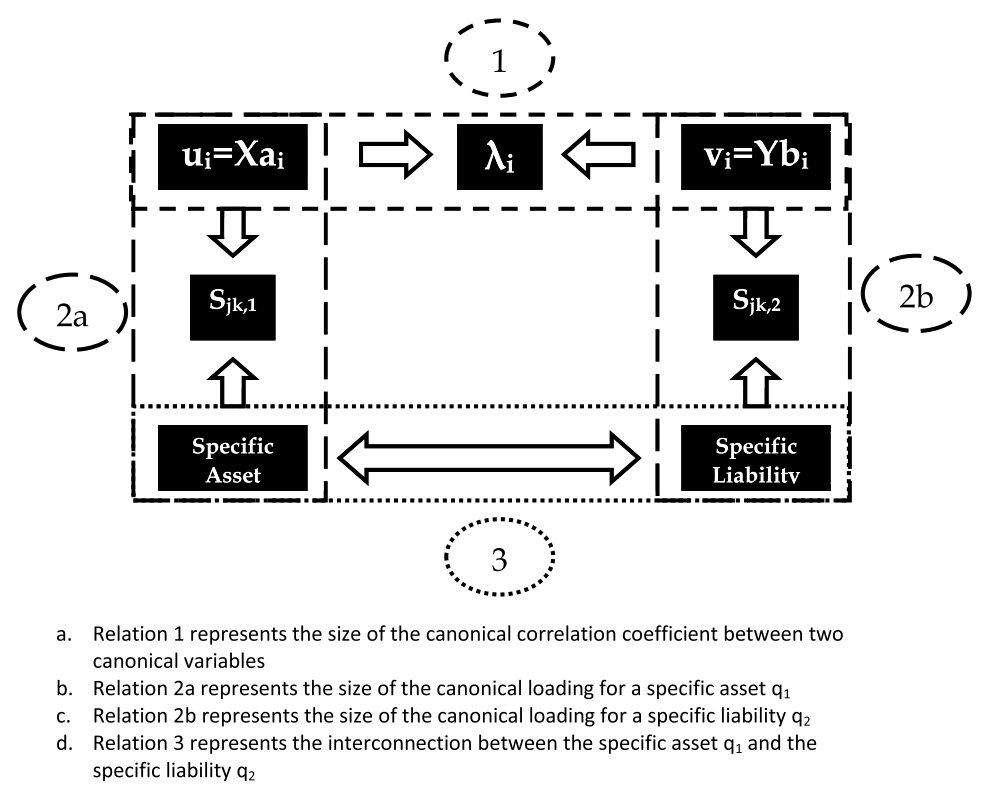

Fig. 1. Relationship between a specific asset and a specific liability. 
Since the canonical correlation coefficients represent the variance shared by linear combinations of asset and liability/capital variables and not the variance shared by the original asset and liability accounts, it is possible that a high correlation between only one asset variable and only one liability variable could lead to a very large canonical correlation coefficient. In order to address this issue and further investigate the links between asset and liability accounts, we calculate the redundancy coefficients that provide a measure of the average ability of asset (liability) variables, taken as a set, to explain variation in liability (asset) variables taken one at a time. For each canonical correlation coefficient $(k=1, \ldots, p)$, the redundancy coefficients can be obtained as follows:

$$
\begin{gathered}
R_{1 k}=\frac{\sum_{j=1}^{q 1} s_{j k, 1}^{2}}{q_{1}} \cdot R_{k}^{2}, \\
R_{2 k}=\frac{\sum_{j=1}^{q 2} s_{j k, 2}^{2}}{q_{2}} \cdot R_{k}^{2}, \\
k=1, \ldots, p,
\end{gathered}
$$

where $s_{j k, 1}^{2}$ and $s_{j k, 2}^{2}$ are, respectively, the elements of matrices $S_{1}$ and $S_{2}$ and $R^{2}$ is the canonical correlation coefficient. As shown by Stewart \& Love (1968), the sum of the redundancy coefficients across all the canonical correlation coefficients represents a measure of the proportion of the variance of asset variables predictable from liability variables $\left(R_{1}\right)$ and vice versa $\left(R_{2}\right)$. In symbols:

$$
\begin{aligned}
& R_{1 k}=\sum_{k=1}^{p} R_{1 k}, \\
& R_{2}=\sum_{k=1}^{p} R_{2 k} .
\end{aligned}
$$

\section{Data and Descriptive Statistics}

We analyze the asset-liability relationships and trends for 24 EU life insurers between 2007 and 2015, using year-end data from companies' balance sheets taken from Bureau van Dijk's Osiris database. Our sample is constructed starting from data for all the countries in the European Union. We then select only life insurance companies for which we have balance sheet data for the years 2007, 2011, and 2015. This results in a final sample of $24 \mathrm{EU}$ life insurers from the following 11 countries: Austria, Germany, Denmark, Spain, Finland, France, United Kingdom, Italy, Netherland, Poland and Slovenia. Based on the OECD statistics, as of the end of 2015, our sample represents circa $56 \%$ of the total assets of the overall European insurance industry. We place a special emphasis on three separate cross sections of data in 2007, 2011 and 2015. Examining the data in 4-year intervals allows sufficient time to pass between 
observations for asset-liability relationships react (or not react) to important changes in financial markets, such as the evolution of interest rate term structure. In order to consider stable balance sheets, following what done in Brislin \& Santomero (1991) with regard to the banking sector, we include in our sample only companies more than 10 years old.

We perform canonical correlation analysis on these data in each year from 2007 to 2015 , where each set of annual calculations is independent from the others. In order to ensure that our findings will reflect the impact of changes in financial markets on asset-liability dependence while holding (as best possible) insurer management and business strategy constant, the models are estimated only for survivor insurers that appear in the data every year during the sample period.

We subdivide insurer assets into the following eight accounts: cash and deposits with credit institutions, bonds and other fixed interest securities, shares and other variable interest instruments, assets held to cover linked liabilities, mortgage loans, real estate loans, receivables arising out of insurance/reinsurance operations and other assets. As concerns the liability side, we have taken into consideration the following six accounts: capital, life reserves, provisions for linked liabilities, payables arising out of insurance/reinsurance operations, external borrowing and other liabilities. Since there is not any a priori to define these accounts prior to applying canonical correlation analysis, we make our decisions based primarily on their nature and maturity characteristics. Each of these accounts is expressed as a percentage of total assets.

The mean balance sheet proportions for this balance sheet breakdown are shown in Table 1. Our sample intermediaries' major investments are in bonds and other fixed rate securities (BOND), which increase over the 2007-2015 time horizon from $38.4 \%$ to $47.8 \%$ of total assets, with a $2.49 \%$ compound annual growth rate. The percentage of assets invested in shares and other variable interest securities (SHARE) experience a decline from the $11.8 \%$ observed in 2007 to the $5.6 \%$ of the 2015 year-end, with a $-7.94 \%$ compound annual growth rate. Overall, the decreasing interest rates and the raise in uncertainty and stock market volatility can explain these opposite trends. The former might have created incentives to buy fixed-rate bonds and securities in order to benefit from capital gains that insurers might have reasonably perceived as highly likely to occur, whereas the latter might have discouraged risky investments in volatile stock markets and less profitable variable interest securities. EU life insurers might have also decided to use their liquidity to support their investments in bonds and fixed rate securities since cash and deposits with credit institutions (CASH) shows a substantial decrease of $10.14 \%$ at a $-1.18 \%$ compound annual growth rate, being, on average the $4.79 \%$ of total assets.

Assets held to cover linked liabilities (AHCLL) are an important share of our insurers' balance sheets, representing the $11.8 \%$ of their total assets over the entire sample period. Their compound annual growth rate is $0.74 \%$, which is very close to the $0.79 \%$ value observed for the correlated item provisions for linked liabilities (PLL) within the liability side. On average, the sum of mortgage and real estate loans 
(ML and REL, respectively) represent $10.6 \%$ of total assets, with an overall $7.98 \%$ decrease to the $9.46 \%$ of the 2015 year-end from the $10.28 \%$ as of December 2007 . By focusing on the receivables and payables arising out of insurance/reinsurance operations, EU life insurers seem to be more involved in transferring their risk to other insurers/reinsurers rather than to take risk from other companies. Receivables from insurance/reinsurance operations are, on average, $2.67 \%$ of total assets, with a compound annual growth rate of $-2.16 \%$, whereas payables represent the $1.73 \%$ of total assets, with an even greater negative compound annual growth rate $(-3.07 \%)$.

On the liability side, the capital endowment (CAPITAL) of our insurance companies has remained quite stable, being equal to $10.7 \%$ at the end of 2007 and to $10.1 \%$ as of December 2015, and representing, on average, $9.86 \%$ of total assets. Prior literature hypothesized a positive relationship between the level of an insurer's capital and its investments in riskier assets such as stocks (Stowe 1978). Therefore, the reduction in shares and variable interest securities, as well as the reduction of lending exposure, might help to explain the substantial stability of EU life insurers'

Table 1. Balance sheet proportions.

\begin{tabular}{|c|c|c|c|c|c|c|c|}
\hline \multirow[t]{2}{*}{ Variable } & \multicolumn{2}{|c|}{2007} & \multicolumn{2}{|c|}{2011} & \multicolumn{2}{|c|}{2015} & \multirow[t]{2}{*}{$\mathrm{N}$} \\
\hline & mean & $\mathrm{sd}$ & mean & $\mathrm{sd}$ & mean & sd & \\
\hline $\mathrm{CASH}$ & 0.046 & 0.049 & 0.055 & 0.044 & 0.041 & 0.030 & 24 \\
\hline BOND & 0.384 & 0.152 & 0.425 & 0.129 & 0.478 & 0.114 & 24 \\
\hline SHARE & 0.118 & 0.083 & 0.052 & 0.047 & 0.056 & 0.065 & 24 \\
\hline AHCL & 0.124 & 0.118 & 0.115 & 0.094 & 0.132 & 0.106 & 24 \\
\hline $\mathrm{ML}$ & 0.075 & 0.124 & 0.084 & 0.123 & 0.069 & 0.098 & 24 \\
\hline REL & 0.028 & 0.027 & 0.028 & 0.025 & 0.025 & 0.016 & 24 \\
\hline IRR & 0.026 & 0.023 & 0.029 & 0.026 & 0.021 & 0.017 & 24 \\
\hline $\mathrm{OA}$ & 0.201 & 0.155 & 0.213 & 0.106 & 0.177 & 0.095 & 24 \\
\hline CAPITAL & 0.107 & 0.095 & 0.092 & 0.076 & 0.101 & 0.068 & 24 \\
\hline LIFERES & 0.439 & 0.191 & 0.461 & 0.189 & 0.471 & 0.181 & 24 \\
\hline PLL & 0.122 & 0.113 & 0.113 & 0.082 & 0.130 & 0.095 & 24 \\
\hline IRP & 0.020 & 0.019 & 0.017 & 0.013 & 0.015 & 0.013 & 24 \\
\hline $\mathrm{EB}$ & 0.020 & 0.019 & 0.022 & 0.016 & 0.020 & 0.011 & 24 \\
\hline $\mathrm{OL}$ & 0.312 & 0.145 & 0.317 & 0.153 & 0.282 & 0.147 & 24 \\
\hline
\end{tabular}

Notes: All variables are expressed as a percentage of total assets and are calculated based on year-end data.

CASH includes cash at the insurer and deposits with credit institutions; BOND contains bonds and other fixed interest securities, SHARE indicates shares and other variable interest instruments, AHCL is made up of assets held to cover liabilities; ML indicates mortgage loans; REL includes real estate loans; IRR consists of receivables arising out of insurance/reinsurance operations; OA is the residual item which includes the rest of the asset items; CAPITAL includes paid up capital, both nondistributable and distributable reserves, other reserves and retained earnings; LIFERES indicates life insurance reserves; PLL refers to the provisions for linked liabilities; IRP is made up of payables arising out of insurance/reinsurance activity; EB includes external borrowing and OL takes into account the rest of the liability accounts. 


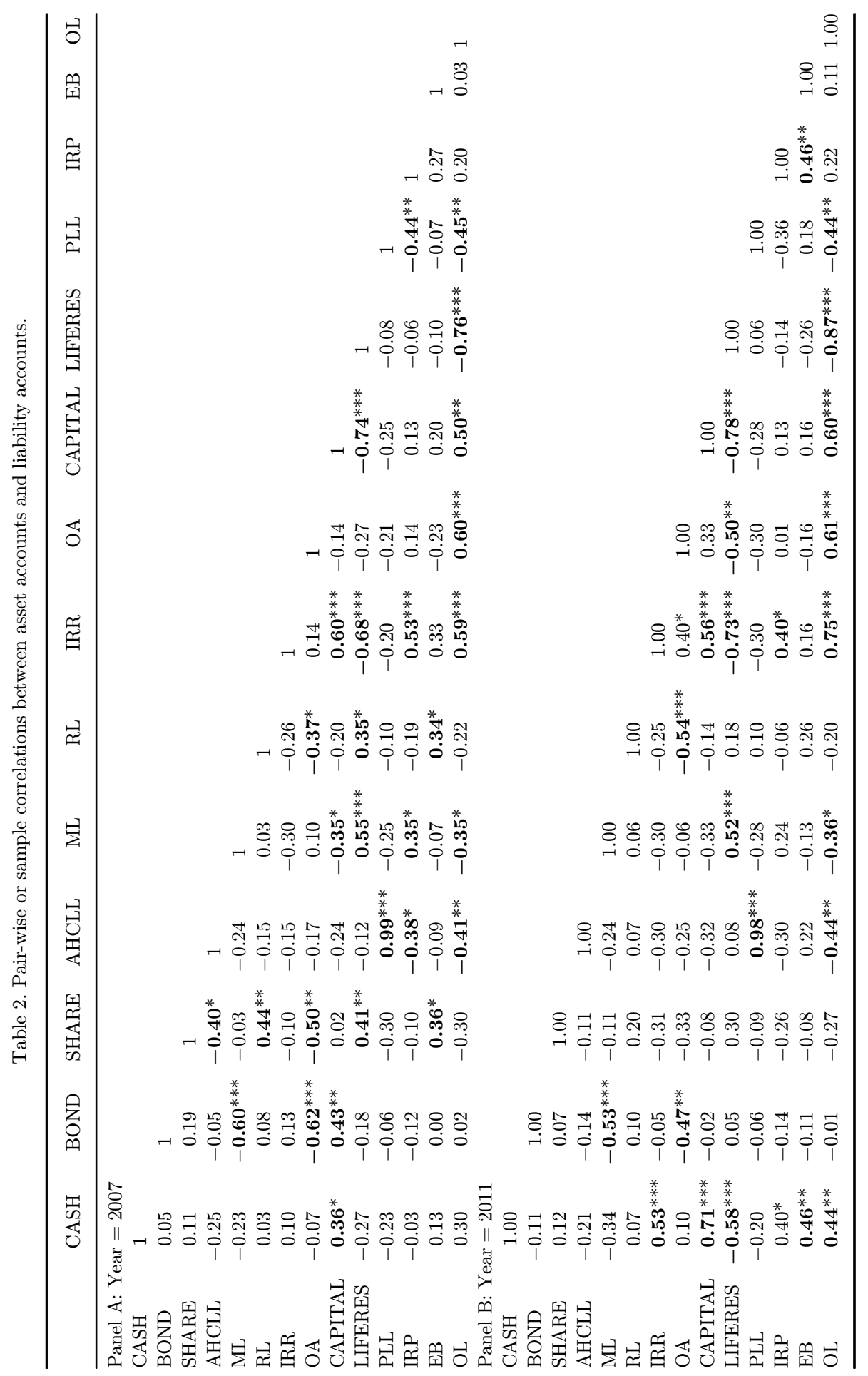




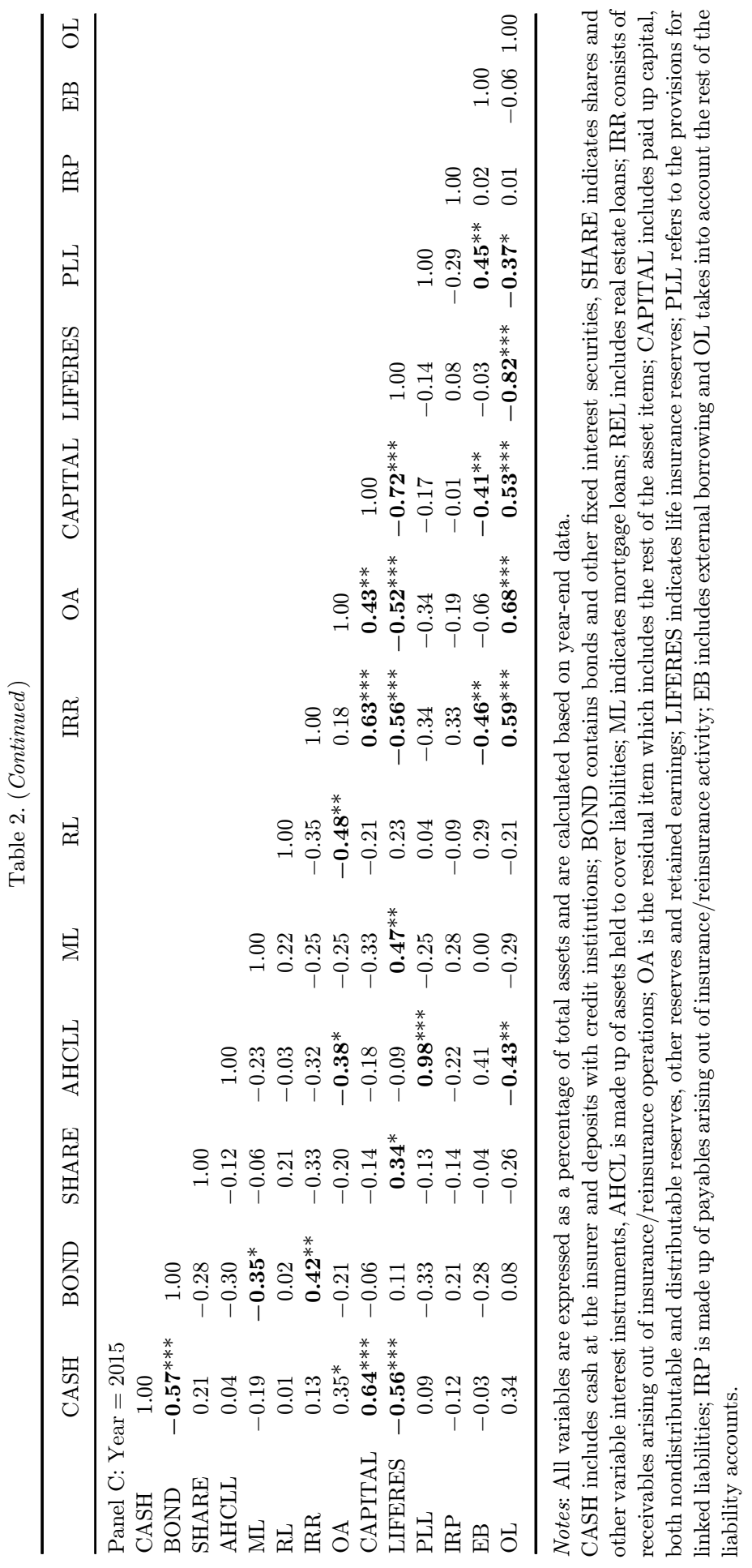




\section{Curcio et al.}

capital endowment, assuming that they have bought high-quality bonds and fixed rate securities.

Life insurance reserves (LIFERES) represent the major share of the balance sheet liability side, amounting, on average, to $45.7 \%$ of total assets, and raising from $43.9 \%$ to $47.1 \%$ over the period we take into account. Finally, PLL represent another significant component of EU life insurers' liabilities, being on average equal to $11.78 \%$ of their total assets, and experiencing a $7.38 \%$ increase from 2007 to 2015 . Both of these two latter accounts show a $0.79 \%$ compound annual growth rate. Finally, the average share of external borrowing is $2.13 \%$ over the entire sample period, with an overall $-0.35 \%$ reduction and an approximately null compound annual growth rate.

Table 2 provides simple correlations between the asset and liability proportions for the cross-section of our sample EU life insurers in each of the major years taken into account. We have highlighted in bold only "strong" correlations, which we define in ad hoc fashion as correlations greater than 0.30 in absolute value and statistically significant. By focusing on the relationships between asset and liability accounts, we only find five relationships confirmed for all the three years 2007, 2011 and 2015. In particular, EU life insurers systematically show an almost perfect positive correlation between AHCLL and PLL, a positive correlation between the variable CASH and the variable CAPITAL, and, finally, a positive correlation between mortgage loans (ML) and LIFERES. Insurance/reinsurance receivables (IRR) positively correlates with CAPITAL and negatively with LIFERES. Among the correlations of the other major asset accounts, the share of bonds and other fixed rate securities (BOND) positively correlates with the amount of capital, reserves and retained earnings (CAPITAL) only in 2007, whereas the variable SHARE positively correlates with LIFERES in 2007 and 2015, but not in 2011. From simple pair-wise correlation analysis, where we completely ignore movements and co-movements of other assets and liabilities, we move to canonical correlation analysis, which considers simultaneously the economic complexities both within and across the two sides of the balance sheet.

\section{Applying Canonical Correlation Analysis to EU Life Insurance Companies: Analysis and Results}

The results of the canonical correlation analysis are discussed in this section. Five canonical variate pairs were derived for our sample insurers, since we have eight variables describing the asset side and six variables for the liability side of the balance sheet, and one was dropped from each group to avoid the singularity issue. ${ }^{\mathrm{b}}$ Table 3 displays the canonical correlations referred to the three main years in our data.

On average, based on the magnitude and statistical significance of the canonical correlation coefficients referred to years 2007, 2011 and 2015, the asset and liability

\footnotetext{
b See Sec. 3 above.
} 
variables exhibit a relatively high degree of collective dependence. For example, the second canonical correlation in the column referred to year 2007 is equal to 0.93 , which means that the second factor extracted from the asset accounts data and the second factor extracted from the liability accounts data have a linear correlation of 0.93. Moving down each column, the canonical correlations tend to decline in both explanatory power and statistical significance. For example, with regard to the 2011 column, the first approximate $F$-statistic of 5.95 allows us to reject the null hypothesis that all the five canonical correlations coefficients are zero. Similarly, the second $F$-statistic of 2.60 rejects the null hypothesis that second, third, fourth, and fifth canonical correlations coefficients are zero. The third $F$-statistic is also statistically significant at the $10 \%$ confidence level, which allows to reject the null hypothesis that third, fourth, and fifth canonical correlation coefficients are zero, but the fourth $F$-value is not: therefore, three or fewer, out of five, canonical pairs are necessary to represent the asset-liability relationship in that particular year. Overall, we find that the number of statistically significant canonical correlations declines over our sample period. In particular, we observe five statistically significant canonical correlation coefficients in 2007, with the coefficients $0.99,0.93,0.83$ and 0.65 all significant at the $1 \%$ confidence level and the coefficient 0.55 marginally significant at the $10 \%$. There are three statistically significant canonical correlation coefficients in 2011, with the coefficients 0.99 and 0.89 both significant at the $1 \%$ confidence level, and the coefficient 0.79 at the $10 \%$. Finally, there are only two statistically significant canonical correlation coefficients in 2015, 0.99 and 0.94, both significant at the $1 \%$ confidence level. Overall, this evidence suggests a declining trend in the strength of the asset-liability relationship within EU life insurers.

Table 3. Canonical correlations.

\begin{tabular}{|c|c|c|c|c|c|c|}
\hline \multirow[t]{2}{*}{ Roots } & \multicolumn{2}{|c|}{2007} & \multicolumn{2}{|c|}{2011} & \multicolumn{2}{|c|}{2015} \\
\hline & $\begin{array}{l}\text { Canonical } \\
\text { correlation }\end{array}$ & $F$-statistic & $\begin{array}{l}\text { Canonical } \\
\text { correlation }\end{array}$ & $F$-statistic & $\begin{array}{l}\text { Canonical } \\
\text { correlation }\end{array}$ & $F$-statistic \\
\hline 1 through 5 & $0.99 * * *$ & 10.59 & $0.99^{* * *}$ & 5.95 & $0.99 * * *$ & 7.57 \\
\hline 2 through 5 & $0.93^{* * *}$ & 4.26 & $0.89 * * *$ & 2.60 & $0.94^{* * *}$ & 3.16 \\
\hline 3 through 5 & $0.83^{* * *}$ & 2.90 & $0.79^{*}$ & 1.75 & 0.77 & 1.42 \\
\hline 4 through 5 & $0.65^{* * *}$ & 2.18 & 0.53 & 0.89 & 0.44 & 0.57 \\
\hline 5 through 5 & $0.55^{*}$ & 0.06 & 0.00 & - & 0.00 & - \\
\hline
\end{tabular}

The $F$-statistic tests whether there is any association between the $p$ pairs of canonical variables. Note: ${ }^{* *},{ }^{* *}, *=$ significance level of $1 \%, 5 \%$, and $10 \%$, respectively, using Bartlett's Chi-square test.

Nevertheless, the statistics displayed in Table 3 represent relationships between linear combinations of asset variables and linear combinations of liability variables, and these canonical correlations may or may not indicate systematic relationships between or among the underlying asset and liability variables. Consequently, in order to address this particular issue, and provide support to the inference we make 


\section{Curcio et al.}

through our statistical analysis, we report information for the proportion of variance coefficients and the redundancy coefficients in Table 4. By construction, the proportion of variance statistics in the Panel A of Table 4 must sum to $100 \%$, and, in order to correctly read the table, we point out that the larger is the number of the reported significant loadings, the more interconnected are our insurers' assets and liabilities.

In 2007 , about $55.2 \%(21.45 \%+25.57 \%+8.15 \%)$ of the variation in the actual assets data is explained by the asset canonical variables in the first three loadings. Four years later, in 2011, a higher percentage of $86.8 \%(37.19 \%+49.65 \%)$ of the variation in the actual assets is explained by the asset canonical variables in the first two loadings. Finally, in 2015, 50.3\% of the variation in the actual assets is explained by the asset canonical variables in the first loading. As far the liability side is concerned, $60.5 \%(25.96 \%+20.70 \%+13.81 \%)$ of the variation in the actual liabilities data is explained by the liability canonical variables in the first three loadings. In $2011,79.9 \%(45.92 \%+34.03 \%)$ of the variation in the actual liabilities is explained by the liability canonical variables in the first two loadings. At the end of our sample period, $66.7 \%$ of the variation in the actual liabilities is explained by the liability canonical variables in the first loading. All else equal, this suggests that the relationships among the various asset and liability accounts become less complex over time, since we observe a reduction in the number of significant loadings and, accordingly, an increase in the share of the variance explained by the first loadings.

Panel B of Table 4 shows the redundancy coefficients calculated following the approach described in the previous Sec. 3 (Stewart \& Love 1968), where we have pointed out that the sum of these coefficients across all the canonical correlation coefficients represents a measure of the proportion of the variance of asset variables predictable from liability variables and vice versa. In other words, redundancy coefficients are a measure of the average capacity of asset (liability) accounts, taken as a set, to explain variation in liability (asset) accounts taken one at a time. Therefore, they are expected to provide insights about the link of causality working between the two sides of our insurers' balance sheets.

The redundancy coefficients in the panel B of Table 4 sum to well less than $100 \%$ across the loadings for all the years taken into account. In 2007, the liability canonical variables explain $51.45 \%$ of the variation in the asset variables, while the asset canonical variables explain $67.4 \%$ of the variation in the liability variables. Both the share of the variation of the asset variables explained by the liability variables and that of the variation of the liability variables explained by the asset variables experience a decline in 2011 and 2015. In particular, with regard to 2011, liability variables explain $40.02 \%$ of the variation of the asset variables and asset accounts are able to explain $61.89 \%$ of the variation of the liability ones, whereas in 2015 these values decrease to $34.19 \%$ and $56.99 \%$, respectively.

Overall, we can draw two informal inferences from the results shown in Table 4. First, causation runs more strongly from assets to liabilities than from liabilities to assets since, for all the three years examined, the variation of the liabilities explained 


\section{Curcio et al.}

by the assets is higher than the variation of the assets explained by the liabilities. In terms of our life insurers' behavior, this seems to suggest that they seek funding and/or determine funding mix only after finding investment opportunities rather than being pools of deposits looking for lending opportunities. Second, despite the relatively large size of the redundancy coefficients, the importance of the first loadings in the calculation of these coefficients, suggests that a relatively small number of relationships among individual asset and liability accounts drives the strong canonical correlations shown in Table 3.

We look more closely at links between the individual asset and liability accounts in Table 5, which focuses on the individual asset-liability relationships in the

Table 5. Correlations of original variables with canonical variables. Sorted varimax rotated canonical loadings.

\begin{tabular}{|c|c|c|c|}
\hline \multicolumn{2}{|c|}{ Assets } & \multicolumn{2}{|c|}{ Liabilities and capital } \\
\hline \multicolumn{4}{|c|}{ Panel A: Year $=2007$} \\
\hline \multicolumn{4}{|c|}{ Canonical variable $1 \mathrm{R}$} \\
\hline IRR & 0.7910 & CAPITAL & 0.7064 \\
\hline CASH & 0.3827 & $\mathrm{~EB}$ & 0.2388 \\
\hline BOND & 0.2375 & IRP & 0.1078 \\
\hline AHCLL & 0.0305 & PLL & -0.0062 \\
\hline RL & -0.2521 & LIFERES & -0.9823 \\
\hline SHARE & -0.3076 & & \\
\hline ML & -0.6906 & & \\
\hline \multicolumn{4}{|c|}{ Canonical variable $2 \mathrm{R}$} \\
\hline AHCLL & 0.9832 & PLL & 0.9802 \\
\hline BOND & -0.0619 & $\mathrm{~EB}$ & 0.0106 \\
\hline IRR & -0.0852 & LIFERES & -0.0867 \\
\hline RL & -0.1344 & CAPITAL & -0.201 \\
\hline ML & -0.1743 & IRP & -0.2736 \\
\hline CASH & -0.256 & & \\
\hline SHARE & -0.3033 & & \\
\hline \multicolumn{4}{|c|}{ Panel B: Year $=2011$} \\
\hline \multicolumn{4}{|c|}{ Canonical variable $1 \mathrm{R}$} \\
\hline CASH & 0.9261 & CAPITAL & 0.9424 \\
\hline IRR & 0.3571 & $\mathrm{~EB}$ & 0.3321 \\
\hline SHARE & 0.1556 & IRP & 0.1294 \\
\hline BOND & 0.0107 & PLL & -0.0809 \\
\hline AHCLL & -0.127 & LIFERES & -0.6329 \\
\hline RL & -0.1422 & & \\
\hline ML & -0.4778 & & \\
\hline \multicolumn{4}{|c|}{ Canonical variable $2 \mathrm{R}$} \\
\hline AHCLL & 0.9823 & PLL & 0.9849 \\
\hline $\mathrm{RL}$ & -0.0165 & $\mathrm{~EB}$ & 0.2211 \\
\hline BOND & -0.0804 & LIFERES & -0.0159 \\
\hline CASH & -0.0981 & CAPITAL & -0.1939 \\
\hline SHARE & -0.1542 & IRP & -0.2207 \\
\hline IRR & -0.2045 & & \\
\hline ML & -0.2986 & & \\
\hline
\end{tabular}


Table 5. (Continued)

\begin{tabular}{|c|c|c|c|}
\hline \multicolumn{2}{|c|}{ Assets } & \multicolumn{2}{|c|}{ Liabilities and capital } \\
\hline \multicolumn{4}{|c|}{ Panel C: Year $=2015$} \\
\hline \multicolumn{4}{|c|}{ Canonical variable $1 \mathrm{R}$} \\
\hline CASH & 0.9688 & CAPITAL & 0.8861 \\
\hline IRR & 0.2543 & PLL & -0.0008 \\
\hline SHARE & 0.2266 & IRP & -0.0675 \\
\hline RL & 0.1244 & $\mathrm{~EB}$ & -0.1521 \\
\hline AHCLL & -0.0339 & LIFERES & -0.4966 \\
\hline ML & -0.2124 & & \\
\hline BOND & -0.3987 & & \\
\hline \multicolumn{4}{|c|}{ Canonical variable $2 \mathrm{R}$} \\
\hline AHCLL & 0.9889 & PLL & 0.9737 \\
\hline CASH & 0.0485 & $\mathrm{~EB}$ & 0.302 \\
\hline RL & -0.0595 & LIFERES & -0.084 \\
\hline SHARE & -0.1501 & CAPITAL & -0.1456 \\
\hline ML & -0.2228 & IRP & -0.1521 \\
\hline IRR & -0.2334 & & \\
\hline BOND & -0.2473 & & \\
\hline
\end{tabular}

Notes: All variables are expressed as a percentage of total assets and are calculated based on year-end data.

CASH includes cash at the insurer and deposits with credit institutions; BOND contains bonds and other fixed interest securities, SHARE indicates shares and other variable interest instruments, AHCL is made up of assets held to cover liabilities; ML indicates mortgage loans; REL includes real estate loans; IRR consists of receivables arising out of insurance/ reinsurance operations; CAPITAL includes paid up capital, both non-distributable and distributable reserves, other reserves and retained earnings; LIFERES indicates life insurance reserves; PLL refers to the provisions for linked liabilities; IRP is made up of payables arising out of insurance/reinsurance activity; EB includes external borrowing.

The left-hand part of the table displays correlations between actual assets account data and the assets canonical variable. The right-hand part of the table displays correlations between actual liabilities account data and the liabilities canonical variable. The correlations are ranked in order of declining absolute value, up to the fourth largest correlation.

canonical loadings for the three years we specifically account for. The interpretation of the relationships in a canonical correlation analysis is often complex. The interpretation of canonical variate pairs is facilitated when the absolute values of the canonical loadings associated with each variate pair consists of a few quite high loadings and a number of quite low ones, and when few variables load substantially on more than one canonical variate pair. This condition can be accomplished to some degree by simultaneously rotating the canonical loadings to a simpler structure. Cliff \& Krus (1976), Fornell \& Larcker (1980) and Perrault \& Spiro (1978) explain the rotation of the canonical loadings. In this study, the canonical loadings are 


\section{Curcio et al.}

rotated using Kaiser's (1958) normalized varimax criterion which leaves the total predictable variance unchanged. The rotated loadings are given, for each of the three years 2007, 2011 and 2015, in the columns of Panels A, B and C of Table 5, and the interpretations are drawn from these rotated loadings.

Given our results in Table 4, we limit our analysis here to the linkages suggested by the first and the second loadings. Correlations between individual actual asset accounts and their asset canonical variables appear on the left-hand side of the tables, while correlations between individual actual liability accounts and their liability canonical variables appear on the right-hand side of the tables. Based on the logic of Fig. 1, finding simultaneous strong canonical loadings for asset and liability accounts implies a strong relationship between the underlying asset and liability variables, because the canonical correlations in both the first and second loadings are empirically large and statistically strong (see Table 3). Following Fornell \& Larcker (1980), we use a 0.30 threshold to determine a "strong" relationship between the original variables and the canonical variables.

We find a limited number of strong and economically sensible relationships among the variables in Table 5 . In particular, for canonical variable $1 \mathrm{R}$, the dominant relationship is between cash and deposits with credit institutions (CASH) and capital and reserves (CAPITAL), which have strong canonical loadings with the same sign in all the three years taken into account, thus providing a strong evidence that these two balance sheet accounts systematically move up and down together. According to this evidence, insurers with large amounts of capital are better able to hold large portions of their portfolios in cash. Function $2 \mathrm{R}$ in all the panels of Table 5 has a positive loading for the AHCLL on the asset side and a positive loading for the PLL on the liability side. Both variables have loadings of nearly unity and all other

original variables have relatively low loadings with this canonical variable. This almost perfect matching of these two accounts is entirely expected as insurers have hedged this asset and liability category.

\section{Concluding Remarks}

Low interest rates have become a significant threat to the stability of the life insurance industry, especially in countries where products with relatively high guaranteed returns sold in the past still represent a prominent share of the total portfolio. Given the current market environment and the expected persistence of extremely low interest rate scenario, it is important to investigate and quantify how and to what extent the unprecedented market conditions have affected life insurers' behavior in terms of asset and liability management.

Canonical correlation analysis has allowed us to examine and interpret significant empirical relationships within the asset and liability structures of a group of large life insurers and the cross-balance sheet relationships that we have identified suggest some interesting considerations, which can shed some light on insurers' decisions under unprecedented market conditions. In particular, contrary to expectations, 
insurance companies seem to run their business as if they decide their funding policies after identifying good investment opportunities. Overall, low market rates may have a negative impact on companies' business model. We find strong and substantial evidence that insurer assets and liabilities have indeed become more independent over time. We argue that the declining trend of market interest rates over the examined time horizon has contributed to the generalized reduction in the linkage between the asset side and the liability side of EU life insurers, and has made insurance companies more exposed to ALM-related risks than they were in the period before the financial crisis broke out.

Based on our findings, further investigation and a deeper comprehension of the relations between insurer assets and liabilities are crucial from both a regulatory and supervisory perspective since it might help to define qualitative and quantitative measures of liquidity requirements that are more consistent with insurers' actual behavior, during both benign market conditions and stressed financial markets.

The statistical methodology employed in this paper is completely appropriate for a first examination of the phenomena we are interested in and can supplement the frequently employed regression models in investigating relationships in which the decision outcome involves a set of several variables instead of a single variable. Nevertheless, our findings should be interpreted with caution since further investigation into asset-liability linkages is needed in order to generate more robust insurerlevel evidence and to get a more comprehensive understanding of the different channels through which interest rates affect life insurers' activity. One potential development would be to apply canonical correlation analysis to time-series data at the insurer level. Such an approach would generate insurer-specific estimates of canonical correlations and redundancy coefficients, which could then be regressed on insurer-specific arguments to test a variety of hypotheses.

\section{Acknowledgements}

The authors would like to thank Eurovita S.p.A. for the useful discussions with its staff on life insurers' ALM practice and for the support to this study.

\section{References}

T. W. Anderson (2003) An Introduction to Multivariate Statistical Analysis. Hoboken: John Wiley \& Sons, Inc.

P. Antolin, S. Schich \& J. Yermo (2011) The economic impact of protracted low interest rates on pension funds and insurance companies, OECD Journal: Financial Markets Trends 2011 (1), 1-20.

D. Bauer, R. Kiesel, A. Kling \& J. Ru (2006) Risk-neutral valuation of participating life insurance contracts, Insurance: Mathematics and Economics 39 (2), 171-183.

M. S. Bartlett (1941) The statistical significance of canonical correlations, Biometrika 32, 29-38.

E. Berdin (2016) Interest rate risk, longevity risk and the solvency of life insurers, ICIR Working Paper Series No. 23/2016. 


\section{Curcio et al.}

E. Berdin \& H. Gründl (2015) The effects of a low interest rate environment on life insurers, The Journal of Financial Regulation and Compliance 40 (3), 385-415.

E. Berdin, C. Kok, K. Mikkonen, C. Pancaro \& J. M. Vendrell Simon (2015) Euro area insurers and the low interest rate environment, ECB Financial Stability Review November, $133-145$.

P. Brislin \& A. Santomero (1991) De novo banking in the Third District. Federal Reserve Bank of Philadelphia, Business Review January, 3-12.

N. Cliff \& D. J. Krus (1976) Interpretations of canonical analysis: Rotated vs. unrotated solutions, Psychometrika, 41 (1), 35-42.

D. Domanski, H. S. Shin \& V. Sushko (2015) The hunt for duration: Not Waving but Drowning? BIS Working Paper.

EIOPA (2014) EIOPA Insurance Stress Test 2014 - November 2014.

EIOPA (2015) Financial Stability Report - December 2015.

EIOPA (2016a) Financial Stability Report - June 2016.

EIOPA (2016b) 2016 EIOPA Insurance Stress Test Report - December 2016.

EIOPA (2018) Financial Stability Report - December 2018.

C. Fornell \& D. Larcker (1980) The use of canonical correlation analysis in accounting research, Journal of Business Finance $\mathcal{E}$ Accounting 7 (3), 455-473.

J. C. Francis (1978) Portfolio analysis of asset and liability management in small-, medium-, and large-sized banks, Journal of Monetary Economiics IV, 460-480.

J. C. Francis \& S. H. Archer (1979) Portfolio Analysis, second edition, Englewood Cliffs, New Jersey: Prentice-Hall, Inc.

T. Gerstner, M. Griebel, M. Holtz, R. Goschnick \& M. Haep (2008) A general asset-liability management model for the e_cient simulation of portfolios of life insurance policies, Insurance: Mathematics and Economics 42 (2), 704-716.

A. Grosen \& P. Løchte Jørgensen (2000) Fair valuation of life insurance liabilities: The impact of interest rate guarantees, surrender options, and bonus policies, Insurance: Mathematics and Economics 26 (1), 37-57.

D. Hartley, A. Paulson \& R. J. Rosen (2016) Measuring interest rate risk in the life insurance sector: The U.S. and the U.K., Working Paper, No. 2016-02, Federal Reserve Bank of Chicago.

H. Hotelling (1935) The most predictable criterion, Journal of Educational Psychology XXVI, 139-142.

H. Hotelling (1936) Relations between two sets of variates, Biometrika XXVIII, 321-377.

A. Kablau \& M. Wedow (2012) Gauging the impact of a low interest rate environment on German life insurers, Applied Economics Quarterly 58 (4), 279-298.

H. F. Kaiser (1958) An index of factorial simplicity, Psychometrika 23, 187-200.

Insurance Europe (2018) European Insurance - Key Facts. Insurance Europe Statistical Publications.

J. H. Lee \& D. R. Stock (2000) Embedded options and interest rate risk for insurance companies, banks and other financial institutions, The Quarterly Review of Economics and Finance 40 (2), 169-187.

A. Mahayni \& D. Steuten (2013) Deferred life annuities: On the combined effects of Stochastic mortality and interest rates, Review of Managerial Science 7 (1), 1-28.

H. M. Markowitz (1952) Portfolio selection, Journal of Finance VII, 77-91.

D. H. Pyle (1971) On the theory of financial intermediation, Journal of Finance XXVI, 737-747.

D. Simonson, J. Stowe \& C. Watson (1983) A canonical correlation analysis of commercial bank asset/liability structures, Journal of Financial \& Quantitative Analysis 18, $125-140$. 
D. Stewart \& W. Love (1968) A general canonical correlation index, Psychological Bulletin 70, $160-163$.

J. D. Stowe (1978) Life insurance company portfolio behavior, Journal of Risk and Insurance 45, 431-477.

J. D. Stowe \& C. J. Watson (1985) A multivariate analysis of the composition of life insurer balance sheets, Journal of Risk and Insurance 52, 222-240.

Swiss Re (2012) Facing the interest rate challenge. Sigma Report, No. 4/2012.

K. Zaglauer \& D. Bauer (2008) Risk-neutral valuation of participating life insurance contracts in a stochastic interest rate environment, Insurance: Mathematics and Economics 43 (1), 29-40. 